\title{
ICMS Ecológico como suporte ao Pagamento por Serviços Ambientais (PSA): uma análise para o estado do Pará
}

Ecological VAT as a form to support the Payment for Environmental Services: an analysis to Pará State

Ynis Cristine de Santana Martins Lino Ferreira - Mestranda do Programa de Pós-Graduação de Gestão dos Recursos Naturais e Desenvolvimento Local na Amazônia pela Universidade Federal do Pará. Especialista em Informação Ambiental. Bolsista de Pesquisa do Instituto de Desenvolvimento Econômico, Social e Ambiental do Pará. E-mail: yniscristine@yahoo.com.br

Mário Vasconcellos Sobrinho - Doutor em Estudos do Desenvolvimento pela Swansea University. Vice Coordenador e Professor do Programa de Pós-Graduação de Gestão dos Recursos Naturais e Desenvolvimento Local na Amazônia, da Universidade Federal do Pará. Professor do Programa de Mestrado de Administração da Universidade da Amazônia. E-mail: mariovasc@ufpa.br

\section{Resumo}

$\mathrm{O}$ artigo discute a implantação do ICMS Ecológico no Estado do Pará como suporte ao financiamento de Pagamento por Serviços Ambientais (PSA). Reflete sobre a possibilidade de repasse de parte desses recursos às comunidades locais, em especial às comunidades residentes em Unidades de Conservação. Assume que essas comunidades produzem benefício público ao contribuírem para a conservação dos recursos naturais. $\mathrm{O}$ artigo conclui que o ICMS Ecológico é um importante instrumento econômico de financiamento de PSA no Pará. Entretanto, apresenta limitações, dificuldades e desafios. Dentre estes, está há necessidade de conciliar a implementação do ICMS Ecológico com políticas públicas que visem à conservação da biodiversidade e suporte ao desenvolvimento dos municípios sob uma nova lógica econômica.

\section{Palavras-chave}

ICMS Ecológico. Pagamento por Serviços Ambientais. Unidades de Conservação.

\begin{abstract}
The paper debates the ICMS Ecológico (Ecological VAT) implementation in Para State as a form to support the Payment for Environmental Services (PES). It deals with the possibility to transfer part of the financial resources to local communities, especially communities that have been living in protected areas. It takes assumption that local communities produce public benefits by contributing to natural resources conservation. The paper concludes that the ICMS Ecológico is a significant economic instrument to support the PSA in Pará. However, it has limitations, difficulties and challenges. There is a need to conciliate the ICMS Ecolológico implementation with a public policy that aims biodiversity conservation and also municípios development from a new economic logic.
\end{abstract}

\section{Keywords}

Ecological VAT. Payment for Environmental Services. Conservation Unity. 


\section{INTRODUÇÃO}

O artigo discute a implantação do ICMS Ecológico como suporte ao Pagamento por Serviços Ambientais (PSA) na Amazônia. Em particular, o artigo analisa a arrecadação do Imposto Sobre Operações Relativas à Circulação de Mercadorias e sobre a Prestação de Serviços de Transporte Interestadual e Intermunicipal e de Comunicações (ICMS) obtida pelo Estado e repassada aos seus diversos municípios. Reflete como este repasse pode contribuir para a manutenção de Unidades de Conservação (UC) de uso sustentável e para a melhoria da qualidade de vida das populações ali existentes. O artigo tem como foco de análise os municípios do estado do Pará que possuem UC.

A proteção ao meio ambiente no Brasil é prevista pelo artigo 225 da Constituição Federal, que estabelece que "todos têm direito ao meio ambiente ecologicamente equilibrado" (BRASIL, 1988). Segundo o artigo constitucional, a competência material comum à proteção do meio ambiente é da União, estados, Distrito Federal e municípios. Assim, os municípios possuem competência legislativa e administrativa para atuar na área ambiental. Todavia, na maioria das vezes, para que as políticas públicas voltadas à área ambiental possam ser implementadas, há necessidade de criação de infraestrutura administrativa, arcabouço legal, previsão orçamentária e disponibilidade financeira. Por isso, para que os municípios possam desenvolver uma política ambiental, é necessário que recursos financeiros sejam alocados em lei orçamentária.

A Constituição Brasileira, no capítulo em que trata do meio ambiente, enfatiza a necessidade de defesa e preservação ambiental, assim como a previsão de mecanismos para que isso ocorra. Como resultado de debates acerca desses mecanismos surgiu a Lei nº 9.985, de 18 de julho de 2000, que instituiu o Sistema Nacional de Unidades de Conservação da Natureza (SNUC). Este sistema regulamenta a criação e a utilização de áreas protegidas destinadas à preservação dos ecossistemas naturais. A Lei no. 9.985 valoriza as características culturais das populações residentes nas unidades de uso sustentável e assegura a participação efetiva das populações locais no processo de criação, implantação e gestão da UC, características essas que podem contribuir decisivamente para o sucesso da gestão destas Unidades. Segundo Brito e Drummond (2007), a gestão das UC deve seguir as regras gerais da administração pública, embora possua especificidades para o seu gerenciamento com a participação das comunidades locais.

Nesse sentido, já há algum tempo, estudam-se, dentro do poder legislativo de vários estados, instrumentos para incentivar a preservação das áreas protegidas por parte dos municípios uma vez que estes podem ser importantes aliados no 
gerenciamento de tais áreas. Entre os instrumentos mais discutidos encontra-se o ICMS Ecológico cuja implantação já ocorreu em diversos estados do Brasil e está em discussão em outros, inclusive no estado do Pará.

O ICMS Ecológico é um instrumento econômico de política ambiental (subsídio), implantado na década de 1990, que consiste em uma parcela resultante da redivisão da receita do ICMS, sob o critério ambiental, aos municípios dos estados (NERY, 2006). Há 12 experiências de implantação do ICMS Ecológico no Brasil (LOUREIRO, 2008). No entanto, ainda são escassos os estudos dessas experiências no país e, em particular, no Pará, estado com legislação em debate para aprovação.

Em vista ao exposto, torna-se imperativo o desenvolvimento de estudos voltados a essa temática, para que seja possível inferir as perspectivas e impactos ocasionados pela implementação do ICMS Ecológico, em particular no estado do Pará, que contemplem a gestão pública e os atores envolvidos no processo. Assim, diante desse quadro, questiona-se: como se apresenta a distribuição do ICMS no estado do Pará? Quais as perspectivas de mudanças a partir da implementação desse instrumento econômico? $\mathrm{O}$ artigo se propõe a responder esses questionamentos.

\section{O CONTEXTO DO ICMS ECOLÓGICO NO BRASIL E PARÁ}

A partir da década de 1980 houve um significativo avanço na legislação ambiental brasileira quanto à responsabilidade para com a defesa e preservação do meio ambiente. Primeiramente, a Lei no 6.938/81 que dispôs sobre a Política Nacional do Meio Ambiente, cujo escopo é preservar a qualidade ambiental propícia à vida, visando assegurar condições ao desenvolvimento socioeconômico, aos interesses da segurança nacional e à proteção da dignidade da vida humana (BORDALO, 2007). Essa Lei, além de estabelecer conceitos, princípios, objetivos, instrumentos e mecanismos de aplicação e de formulação, assumiu a função de garantir a descentralização da gestão ambiental, por meio do compartilhamento entre os Entes Federados (União, estados e municípios) (OLIVEIRA; JÚNIOR; SPENGLER, 2008).

Segundo, a promulgação da Carta Magna de 1988 que estabeleceu a corresponsabilidade da sociedade e do poder público, em seus três níveis, para com a defesa e preservação do meio ambiente. A Carta Magna dedica um capítulo exclusivo ao tema, mais precisamente o artigo 225, que dispõe sobre o direito que todos os cidadãos possuem sobre o meio ambiente natural como elemento essencial à sadia qualidade de vida (BRASIL, 1988). O município se transforma em um 
ente federativo, tendo autonomia política, administrativa e financeira, bem como suas competências legais ampliadas. Configurou-se assim, a descentralização da gestão ambiental no Brasil (TONI; PACHECO, 2005; SILVA, 2007; OLIVEIRA; JÚNIOR; SPENGLER, 2008).

Terceiro, a Lei n. ${ }^{\text {9.985, de }} 18$ de julho de 2000, que instituiu o SNUC, reclassificou as diversas categorias e regulamentou a criação e a utilização de áreas protegidas destinadas à preservação dos ecossistemas naturais. Além desta reclassificação, inovou em outros aspectos, tais como a participação social na criação e gestão de UC, novas formas de tratamento de populações tradicionais que habitam as áreas de proteção, além de prever a alocação de recursos financeiros para tais áreas (BRASIL, 2000).

Quanto à conservação e manutenção de áreas protegidas por parte dos municípios, estudos de Loureiro (2002), sobre o estado do Paraná, mostram que a preservação de uma determinada área demanda alto custo de oportunidade. $\mathrm{Ou}$ seja, pelo menos sob o ponto de vista imediatista, os municípios acabam por abrir mão de atividades tradicionais geradoras de recursos devido ao impacto econômico gerado pela restrição ao uso do solo para atividades rentáveis.

Em 1991 foi adotado o ICMS Ecológico no estado do Paraná, a partir da aliança do Poder Público Estadual e de municípios (LOUREIRO, 2002). Tal mecanismo, em princípio, surgira como um instrumento de compensação aos municípios que enfrentavam dificuldades em incentivar o crescimento econômico tradicional devido à existência de UC. Segundo Loureiro (2008), esse instrumento foi desenvolvido em seguida nos estados de São Paulo (1993), Minas Gerais (1995), Rondônia (1996), Amapá (1996), Rio Grande do Sul (1998), Mato Grosso do Sul (2001), Mato Grosso (2001), Pernambuco (2001), Tocantins (2002), Acre (2007), Rio de Janeiro (2007) e Goiás (2007).

No estado do Pará, desde a promulgação da Constituição Estadual, em 1989, é assegurado para municípios que abriguem UC em seus territórios, "tratamento especial quanto ao crédito das parcelas da receita referenciada no art. 158" da Constituição Federal (PARÁ, 1989), ou seja, do ICMS. Assim, existe a possibilidade legal para a adoção de critérios ambientais na distribuição do imposto pelo estado aos municípios. No entanto, os anos se passaram e ainda inexiste a regulamentação do referido "tratamento especial" por meio de lei estadual.

Destaque-se, porém, que em 1999, por meio de projeto de lei apresentado à Assembleia Legislativa por uma deputada estadual ${ }^{1}$, começou a ser estudada e discutida a implantação do ICMS Ecológico como tentativa de atribuir uma função ambiental, e mesmo social, à arrecadação tributária municipal. O projeto de lei

1 Deputada estadual Maria do Carmo do Partido dos Trabalhadores (PT). 
propunha para a distribuição do ICMS aos municípios, além do Valor Adicionado Fiscal, definido na Constituição Federal, critérios como: (a) UC e outros espaços especialmente protegidos, (b) crianças matriculadas associado a taxas de evasão escolar, (c) sistema de saneamento básico e (d) disponibilidade de leitos hospitalares associada ao coeficiente de mortalidade infantil (PARÁ, s.d.). Contudo, segundo Loureiro (apud FERREIRA; VASCONCELLOS, 2010), o projeto não foi aprovado e uma nova discussão do tema no Estado estaria relacionada a novos critérios, dentre eles o desmatamento evitado.

Posteriormente, outro deputado estadual ${ }^{2}$ elaborou e colocou em debate dois anteprojetos de lei tratando do ICMS Ecológico. O primeiro dispôs sobre a regulamentação do ICMS Ecológico, prevendo benefícios para os municípios que "abriguem em seu território unidades de conservação e aqueles formadores de mananciais". O segundo anteprojeto propunha que o critério ambiental fosse definido em $4 \%$, sendo obtido por meio da redução de $1 \%$ do critério populacional, $1 \%$ do territorial e $2 \%$ do critério igualitário, respectivamente (PARÁ, s.d.). Contudo, ambos não foram aprovados pela Assembléia Legislativa Paraense.

Em uma tentativa de trazer novos elementos para o debate, foi contratada a consultoria de um especialista ${ }^{3}$ no assunto. Os relatórios da consultoria consideraram as possibilidades constitucionais e legais existentes no Estado e sugeriram um novo anteprojeto de lei para o ICMS Ecológico. A minuta de anteprojeto objetivou subsidiar um debate inicial entre a Secretaria de Estado de Meio Ambiente do Pará (SEMA) e a Secretaria de Estado da Fazenda do Pará (SEFA). Tal proposta de anteprojeto aproveitou quase a totalidade das propostas anteriores. Entretanto, acrescenta aspectos relativos às áreas protegidas, incluindo as reservas legais e as áreas de preservação permanente (PARÁ, s/d).

A partir de 2009, tem-se um evento que impulsiona a reflexão acadêmica a respeito deste tema: o Decreto 1.697 de 5 de junho de 2009. Este regulamenta o Plano de Prevenção, Controle e Alternativas ao Desmatamento do Estado do Pará (PPCAD-PA). O Decreto determina até dezembro de 2012 o prazo para implementação do ICMS Ecológico no Estado, de modo transparente e com fiscalização do órgão estadual (PARÁ, 2009).

\footnotetext{
Deputado Airton Faleiro, do Partido dos Trabalhadores (PT).

3 Dr. Wilson Loureiro, do Instituto Ambiental do Paraná (IAP).
} 


\section{PERSPECTIVAS DE ANÁLISE E FUNÇÕES DO ICMS ECOLÓGICO}

Existem pelo menos quatro perspectivas teóricas de análise para definir o significado de ICMS Ecológico. A primeira se refere à perspectiva legalista. Nesta, o ICMS Ecológico é utilizado como um critério de distribuição da cota-parte do ICMS a que os municípios têm direito, conforme estabelece o artigo 158 da Constituição Federal (LOUREIRO, 2002). Este direito se dá pela existência de mananciais de abastecimento, UC ou terras indígenas nos territórios municipais. Segundo Loureiro (2002), o ICMS Ecológico foi originado pela reivindicação de prefeituras que sentiam fragilidades em suas economias pela restrição do uso do solo em seus territórios, em particular, os municípios que possuem mananciais de abastecimento ou UC. De fato, Veiga Neto (2000) chama atenção para a ocorrência de restrições no uso do solo dos municípios que possuem tais características, restrições essas que dificultam as possibilidades de desenvolvimento pela lógica econômica convencional.

Embora não contradiga o viés legalista, a segunda perspectiva de análise entende o ICMS sob o ponto de vista da compensação ambiental. Nesta perspectiva, o ICMS Ecológico nasceu sob a égide da compensação e evoluiu, transformando-se em um instrumento de conservação ambiental (LOUREIRO, 2002), contribuindo para a melhoria da conservação da biodiversidade.

$\mathrm{Na}$ terceira perspectiva de análise, o ICMS Ecológico é interpretado como um subsídio (TUPIASSU, 2003; NERY, 2006). Este se apresenta como um forte instrumento econômico de incentivo fiscal. Tem como objetivo não somente alcançar a finalidade da preservação ambiental prevista na Constituição Brasileira, mas promover a justiça fiscal, isto é, influenciar nas ações voluntárias dos municípios na busca de melhorias da qualidade de vida das populações, por meio do aumento da receita (TUPIASSU, 2003).

Estudos recentes (VEIGA NETO, 2008) apontam para uma quarta perspectiva que considera o ICMS Ecológico como PSA (Pagamento por Serviço Ambiental). Sob essa perspectiva, os proprietários e gestores de áreas e recursos naturais seriam remunerados financeiramente pela conservação da biodiversidade. No estado do Paraná, experimenta-se, ainda de forma embrionária, que parte do ICMS Ecológico gerado pela criação voluntária de reservas privadas possa retornar aos seus proprietários como incentivo econômico direto (VEIGA NETO, 2008).

A literatura (FREITAS apud NERY, 2006) é recorrente em aferir que o ICMS Ecológico possui duas funções principais: (i) compensatória: para compensar municípios que abrigam áreas protegidas em seus territórios, impedindo-os de desenvolver atividades produtivas tradicionais nessas áreas; e, (ii) incentivadora: 
para estimular que os municípios adotem iniciativas de conservação ambiental e desenvolvimento sustentável (FREITAS apud NERY, 2006). No entanto, a partir de estudos desenvolvidos por Veiga Neto (2008), subtende-se uma terceira função, ou seja, a (iii) remuneratória a partir do PSA, na qual há remuneração financeira por meio de incentivo econômico direto pela conservação da biodiversidade.

\section{ICMS ECOLÓGICO ENQUANTO PAGAMENTO POR SERVIÇO AMBIENTAL (PSA)}

Como colocado acima, o ICMS Ecológico tem sido interpretado como uma categoria de PSA (VEIGA NETO, 2008). Nesta perspectiva, o ICMS Ecológico está relacionado às condições e processos pelos quais os ecossistemas sustentam a vida humana (DALY apud WUNDER, 2008) de conservação da biodiversidade.

Segundo Wunder (2008), os esquemas de PSA público se referem àqueles em que o Poder Público atua como comprador intermediário, ou seja, opera quando existe uma externalidade - benefício externo ao provedor de serviços ambientais. No entendimento do autor é imprescindível a existência de uma legislação adequada que institua e regulamente a prática de pagamentos compensatórios, assim como recursos orçamentários para alocação visando esse fim.

Partindo desse pressuposto, Veiga Neto (2008) apresenta o ICMS Ecológico como um mecanismo de compensação ambiental aplicado à conservação da biodiversidade, a partir de uma recente experiência em PSA realizada no estado do Paraná. Este estado regulamentou o repasse direto de recursos oriundos do ICMS Ecológico a que os municípios têm direito aos proprietários das Reservas Particulares do Patrimônio Natural (RPPN). Ou seja, por meio dessa ação é proporcionado apoio à conservação de terras privadas, surgindo, assim, a possibilidade de que parte dos repasses gerados pela criação voluntária dessas reservas possa retornar para a gestão das mesmas.

A partir daí, entende-se que o apoio ao proprietário particular na gestão da sua RPPN, constitui-se em benefício para o município. Isso porque, segundo Veiga Neto (2008), as normas paranaenses definem que os recursos obtidos pelos proprietários de RPPN, a partir do ICMS Ecológico, deverão ser integralmente aplicados na gestão da UC. Assim, na medida em que surge o apoio financeiro para o proprietário de reserva particular, melhora o desempenho da gestão da sua RPPN e, consequentemente, com o surgimento de novas RPPN, melhor o desempenho financeiro do município, que obterá incremento na sua receita. 


\section{AS UNIDADES DE CONSERVAÇÃO NO ESTADO DO PARÁ}

A literatura sobre a influência das políticas desenvolvimentistas do Estado nacional sobre a estrutura econômica, social e territorial do estado do Pará é muito abrangente. Sob todas as perspectivas, boa parte da literatura (BURSZTYN; BURSZTYN; ASSUNÇÃO, 2004, MAUÉS, 1999) aponta para os efeitos que as políticas de desenvolvimento, particularmente aquelas implementadas a partir dos governos militares na década de 1970, trouxeram para o estado do Pará. Dentre tantas consequências, está o alto nível de desmatamento em que o acumulado em 2009 atingiu uma área de $245.035 \mathrm{~km}^{2}$, o que representa 21,6\% do território paraense e 33,28\% do desmatamento da Amazônia Legal (IDESP, 2010b). O avanço do desmatamento no estado durante as décadas de 1980 e 1990 trouxe importantes reações, dentre as quais a criação de UC como forma de conter o avanço na floresta.

Em 2010, aproximadamente 40\% $\left(413.854,63 \mathrm{Km}^{2}\right)$ do território do estado do Pará (1.247.689,5 Km²) estava constituído de UC, sob jurisdição federal, estadual, municipal ou ainda de iniciativa particular (SEMA, 2010). A Figura 1 demonstra a distribuição das UC nos municípios do estado do Pará.

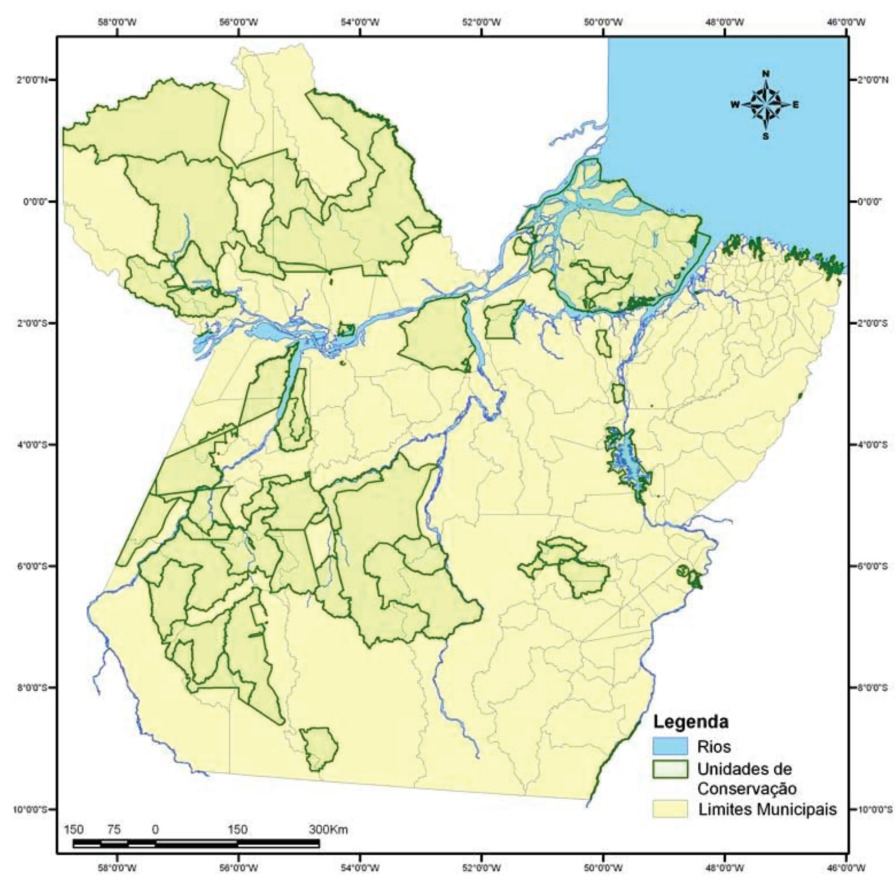

Figura 1 - Distribuição das UC no estado do Pará.

Fonte: FERREIRA; VASCONCELLOS (2010). 
Observa-se, de acordo com dados do Zoneamento Econômico e Ecológico do Estado do Pará (IDESP, 2010), que os municípios com maior extensão de UC em seus territórios são Oriximiná, Altamira, Itaituba, Almeirim e Novo Progresso, respectivamente (Tabela 1).

Tabela 1 - Municípios paraenses com maior extensão territorial de UC.

\begin{tabular}{|c|c|c|c|c|}
\hline Município & $\begin{array}{c}\text { Área de UC } \\
(\mathrm{km} 2)\end{array}$ & Esfera & Categoria & Denominação \\
\hline \multirow[t]{5}{*}{ Oriximiná } & \multirow[t]{5}{*}{$70.013,43$} & Federal & Proteção Integral & Reserva Biológica do Rio Trombetas \\
\hline & & Federal & Uso Sustentável & Floresta Nacional Serac-a-Taquera \\
\hline & & Estadual & Proteção Integral & Estação Ecológica do Grão-Pará \\
\hline & & Estadual & Uso Sustentável & Floresta Estadual de Faro \\
\hline & & Estadual & Uso Sustentável & Floresta Estadual do Trombetas \\
\hline \multirow[t]{9}{*}{ Altamira } & \multirow[t]{9}{*}{$59.443,43$} & Federal & Proteção Integral & Parque Nacional Serra do Pardo \\
\hline & & Federal & Proteção Integral & Reserva Biológica da Serra do Cachimbo \\
\hline & & Federal & Proteção Integral & Estação Ecológica Terra do Meio \\
\hline & & Federal & Uso Sustentável & Floresta Nacional de Altamira \\
\hline & & Federal & Uso Sustentável & Reserva Extratvista Riozinho do Anfrísio \\
\hline & & Federal & Uso Sustentável & Reserva Extrativista Rio Iriri \\
\hline & & Federal & Uso Sustentável & Reserva Extrativista Rio Xingu \\
\hline & & Estadual & Uso Sustentável & Área de Proteção Ambiental Triunfo do \\
\hline & & Estadual & Uso Sustentável & Floresta Estadual do Iriri \\
\hline \multirow[t]{11}{*}{ Itaituba } & \multirow[t]{11}{*}{$45.416,84$} & Federal & Proteção Integral & Parque Nacional da Amazônia \\
\hline & & Federal & Proteção Integral & Parque Nacional Jamanxim \\
\hline & & Federal & Proteção Integral & Parque Nacional do Rio Novo \\
\hline & & Federal & Uso Sustentável & Floresta Nacional Itaituba I \\
\hline & & Federal & Uso Sustentável & Floresta Nacional Itaituba II \\
\hline & & Federal & Uso Sustentável & Floresta Nacional de Altamira \\
\hline & & Federal & Uso Sustentável & Floresta Nacional do Amaná \\
\hline & & Federal & Uso Sustentável & Floresta Nacional do Trairão \\
\hline & & Federal & Uso Sustentável & Área de Proteção Ambiental do Tapajós \\
\hline & & Municipal & Uso Sustentável & Área de Proteção Ambiental Bom Jardim/Passa \\
\hline & & Municipal & Uso Sustentável & Área de Proteção Ambiental Praia do Sapo \\
\hline \multirow[t]{4}{*}{ Almerim } & \multirow[t]{4}{*}{$33.675,98$} & Federal & Proteção Integral & Parque Nacional Montanhas Tumucumaque \\
\hline & & Federal & Proteção Integral & Estação Ecológica do Jari \\
\hline & & Estadual & Proteção Integral & Reserva Biológica Maicuru \\
\hline & & Estadual & Uso Sustentável & Floresta Estadual do Paru \\
\hline \multirow{4}{*}{$\begin{array}{l}\text { Novo } \\
\text { Progresso }\end{array}$} & \multirow[t]{4}{*}{$16.729,24$} & Federal & Proteção Integral & Parque Nacional do Rio Novo \\
\hline & & Federal & Proteção Integral & Reserva Biológica da Serra do Cachimbo \\
\hline & & Federal & Uso Sustentável & Floresta Nacional Jamanxim \\
\hline & & Federal & Uso Sustentável & Área de Proteção Ambiental do Tapajós \\
\hline
\end{tabular}

Fonte: Elaboração própria a partir de SEMA (2010) e IDESP (2010a). 
No Pará, a extensão territorial mais significativa é ocupada pela Área de Proteção Ambiental (APA) (Tabela 2). Segundo o SNUC, a APA possui certo grau de ocupação humana, possuindo o objetivo de proteção da diversidade biológica, disciplinar o processo de ocupação e assegurar a sustentabilidade do uso dos recursos naturais.

Tabela 2 - Configuração das UC no Estado do Pará.

\begin{tabular}{|c|c|}
\hline \multicolumn{2}{|c|}{ Estado do Pará } \\
\hline Classe & Área Total $(\mathrm{Km} 2)$ aproximada \\
\hline Área de Proteção Ambiental & $93.133,76$ \\
\hline Estação Ecológica & $82.079,92$ \\
\hline Floresta Estadual & $59.970,33$ \\
\hline Floresta Nacional & $62.771,15$ \\
\hline Parque Estadual & 213,9 \\
\hline Parque Nacional & $25.181,51$ \\
\hline Proteção Integral & $4.098,47$ \\
\hline Reserva Biológica & $19.883,83$ \\
\hline Reserva Extrativista & $32.778,73$ \\
\hline Uso Sustentável* & $53.771,61$ \\
\hline
\end{tabular}

Fonte: IDESP (2010a).

Nota: *Área sugerida pelo Zoneamento Econômico e Ecológico do Estado do Pará para implantação de UC de uso sustentável.

Ressalte-se, também, a existência da Reserva Extrativista (Tabela 2), utilizada por populações extrativistas tradicionais. Segundo o SNUC, estas populações praticam o extrativismo e, complementarmente, a agricultura de subsistência e criação de animais de pequeno porte.

Outra observação importante é a de que existem municípios onde as UC abrangem mais de 90\% dos seus territórios (Figura 2). Como exemplo disso, podemos citar alguns municípios que compõe o arquipélago do Marajó: Santa Cruz do Arari, Anajás, São Sebastião da Boa Vista, Curralinho e Muaná (IDESP, 2010a). 

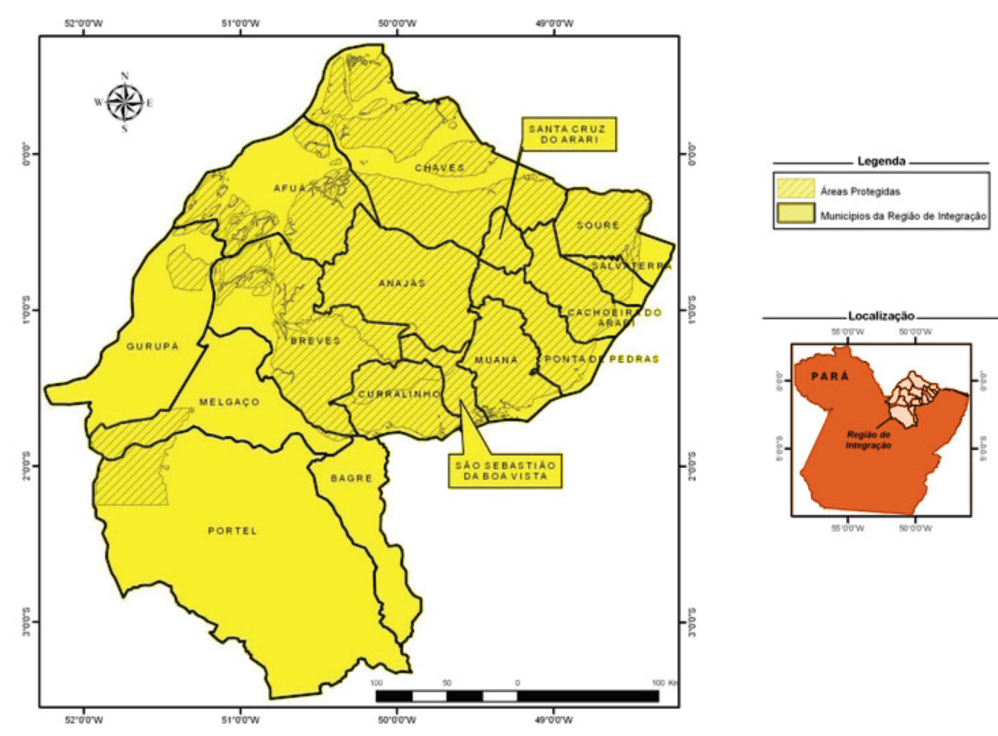

Figura 2 - UC nos municípios da RI Marajó.

Fonte: IDESP (2010c).

\section{AS COTAS-PARTE DE ICMS E AS UNIDADES DE CONSERVAÇÃO NO PARÁ}

A distribuição atual das cotas-parte de ICMS aos municípios paraenses obedece ao disposto no art. 158 da Constituição Federal e à Lei Estadual $\mathrm{n}^{\mathrm{o}} 5.645$ alterada pela Lei Estadual no 6.276 (SEFA, 2010). Segundo o art. $158 \mathrm{da}$ Constituição Federal, 25\% do produto do ICMS pertence aos municípios, devendo ser repassados a estes segundo os seguintes critérios: (a) no mínimo $75 \%$, na proporção do valor adicionado, nas operações relativas à circulação de mercadorias e prestações de serviços realizadas em seus territórios e (b) até $25 \%$ de acordo com que dispuser em Lei Estadual (BRASIL, 1988). Assim, cada estado brasileiro define os critérios de distribuição de $25 \%$ do ICMS, adequados as suas especificidades.

O Valor Adicionado expresso no art. 158 da Constituição Federal é definido, segundo a Lei Complementar $\mathrm{n}^{\circ} 63$, como o valor das mercadorias saídas, acrescido do valor das prestações de serviços no seu território, deduzido o valor das mercadorias entradas, em cada ano civil. Assim, no estado do Pará, a cota-parte referente ao critério do valor adicionado é calculada com base na média geométrica dos índices de participação de cada município no valor adicionado do Estado, apurados nos dois anos civis anteriores à apuração (SEFA, 2010). 
O segundo critério de cota-parte, disposto no art. 158 da Constituição, é regulamentado pela Lei Estadual n ${ }^{\circ}$ 5.645, alterada pela Lei Estadual n ${ }^{\circ} 6.276$. O índice utilizado deve ser apurado observando as seguintes vaiáveis: 5\% na proporção da população de cada município; $5 \%$ na proporção da área de cada município e 15\% distribuídos em partes iguais a todos os municípios (SEFA, 2010).

Percebeu-se, no segundo Semestre de 2009, concentração de aproximadamente $30 \%$ da cota-parte de ICMS para os municípios de Belém e Parauapebas, estando 70\% distribuída entre 141 municípios paraenses (SEFA, 2009), conforme Figura 3. Essa lógica atual de distribuição induz a uma desproporcionalidade e concentração da cota-parte de ICMS nos municípios que possuem maior densidade econômica. Isso porque, como dito anteriormente, o critério constitucional estabelece que, no repasse a que os municípios têm direito, no mínimo 75\%, referem-se à proporção do valor adicionado nas operações relativas à circulação de mercadorias e prestações de serviços realizadas nos territórios.

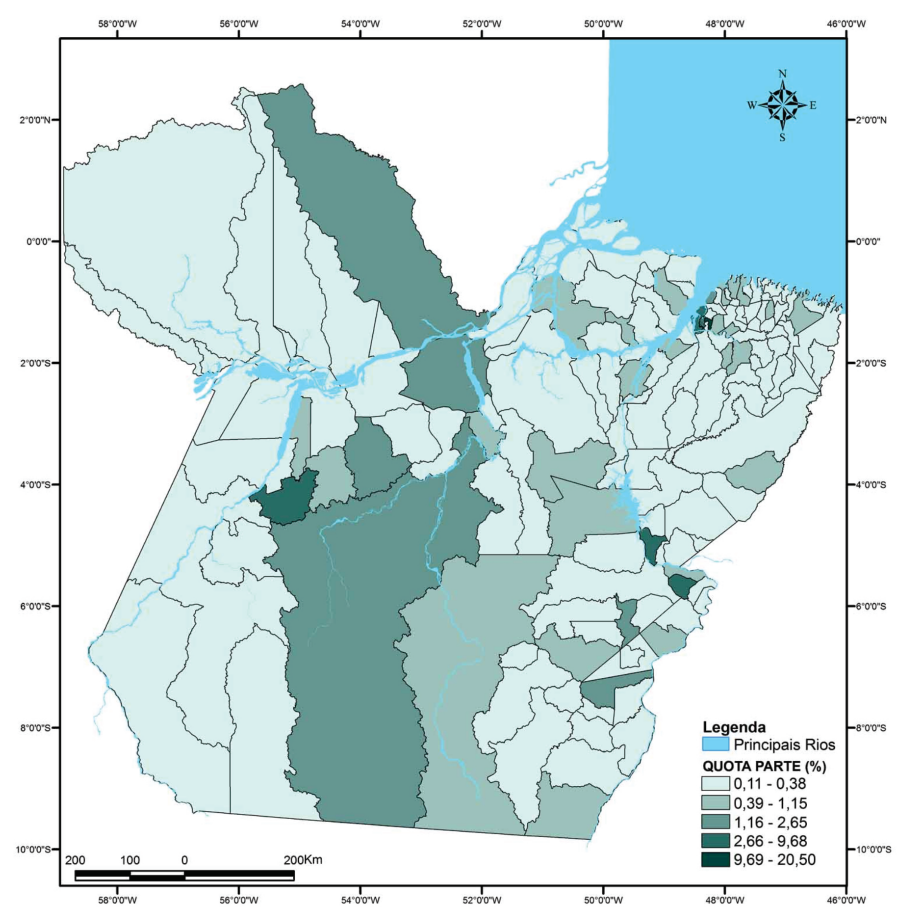

Figura 3 - Distribuição das cotas-parte de ICMS no Pará no segundo semestre de 2009. Fonte: FERREIRA; VASCONCELLOS (2010).

A partir da implantação do ICMS Ecológico no estado do Pará seria estabelecida uma nova lógica para definição do repasse da cota-parte de ICMS 
que cada município tem direito. Desse modo, o critério ambiental estará inserido no segundo critério apontado no art. 158 da Constituição Federal.

Dos quatorze municípios com maior arrecadação de ICMS no exercício financeiro de 2009 (Tabela 3), segundo o IDESP (2010a), onze possuem UC em seus territórios, sendo exceção os municípios de Barcarena, Castanhal e Paragominas.

Tabela 3 - Municípios paraenses com maior arrecadação de ICMS em 2009.

\begin{tabular}{lrc}
\hline Município & Total de ICMS & Cota - Parte $(\%)$ \\
\hline Belém & $184.008,065,76$ & 20,5 \\
Parauapebas & $86.887 .711,05$ & 9,68 \\
Marabá & $57.715 .700,63$ & 6,43 \\
Barcarena & $56.369 .300,15$ & 6,28 \\
Tuuruí & $46.585 .456,65$ & 5,19 \\
Ananindeua & $40.571 .534,50$ & 4,52 \\
Oriximiná & $23.786 .408,50$ & 2,65 \\
Santarém & $19.926 .727,12$ & 2,22 \\
Canaã dos Carajás & $19.118 .886,63$ & 2,13 \\
Altamira & $13.823 .044,94$ & 1,54 \\
Castanhal & $13.553 .764,85$ & 1,51 \\
Paragominas & $12.386 .884,43$ & 1,38 \\
Almeirim & $11.399 .524,07$ & 1,27 \\
Itaituba & $10.322 .403,69$ & 1,15 \\
Demais Municípios (129) & $310.866 .627,43$ & 33,55 \\
\hline
\end{tabular}

Fonte: SEFA (2009).

Em vista do exposto, tecem-se duas ressalvas relacionadas às funções compensatória e incentivadora, quando estas são confrontadas com as especificidades apresentadas pelos municípios paraenses.

A primeira ressalva se refere ao fato de que o ICMS Ecológico possui a função de compensar municípios que abrigam áreas protegidas em seus territórios, impedindo-os de desenvolver atividades produtivas tradicionais nessas áreas (FREITAS apud NERY, 2006). Os resultados acima (Figura 1 e Tabela 3) demonstram que a maioria dos municípios que mais arrecadam ICMS, ou seja, os que possuem maior proporção do valor adicionado, também possuem UC em seus territórios.

Considerando os quinze municípios com menor arrecadação de ICMS no exercício financeiro de 2009 (Tabela 4), observa-se, com base nos dados de IDESP (2010a), que apenas dois possuem UC em seus territórios: Limoeiro do Ajuru e 
Santa Cruz do Arari. Portanto, para esses municípios não há relação proporcional entre a existência de UC e o a arrecadação de ICMS.

Tabela 4 - Municípios com menor arrecadação de ICMS no segundo semestre de 2009 .

\begin{tabular}{lrc}
\hline Município & Total de ICMS & Cota - Parte (\%) \\
\hline Magalhães Barata & $987.360,35$ & 0,11 \\
Santarém Novo & $987.360,35$ & 0,11 \\
São João da Ponta & $987.360,35$ & 0,11 \\
Bonito & $1.077 .120,38$ & 0,12 \\
Colares & $1.077 .120,38$ & 0,12 \\
Peixe-Boi & $1.077 .120,38$ & 0,12 \\
Primavera & $1.077 .120,38$ & 0,12 \\
Quatipuru & $1.077 .120,38$ & 0,12 \\
Santa Cruz do Arari & $1.077 .120,38$ & 0,12 \\
Terra Alta & $1.077 .120,38$ & 0,12 \\
Curuá & $1.166 .880,42$ & 0,13 \\
Inhangapi & $1.166 .880,42$ & 0,13 \\
Limoeiro do Ajuru & $1.166 .880,42$ & 0,13 \\
Nova Timboteua & $1.166 .880,42$ & 0,13 \\
São Caetano de Odivelas & $1.166 .880,42$ & 0,13 \\
Demais Municípios (128) & $890.985 .714,79$ & 98,18 \\
\hline
\end{tabular}

Fonte: SEFA (2009).

É importante salientar que existem municípios que possuem restrições de até $100 \%$ em seus territórios devido à existência de UC, como é o caso de Santa Cruz do Arari (Tabela 5). Nesses casos, o critério ambiental compensará esses municípios impedidos de se desenvolver nos moldes tradicionais. Contudo, o baixo índice de cota-parte não é decorrente da existência unicamente das UC, existindo outras variáveis que contribui para a baixa arrecadação de ICMS.

A segunda ressalva se refere à função incentivadora, em que o ICMS Ecológico é apontado com a função de estimular os municípios a adotarem iniciativas de conservação ambiental e desenvolvimento sustentável, incluindo a criação de novas UC. Isso porque uma extensão territorial significativa do Estado e de 61 de seus municípios é constituída por UC. Assim, no Pará, a reflexão está relacionada não somente ao aumento dessas áreas, mas também referente à qualidade da gestão das UC já existentes.

Portanto, é necessário que se observe os resultados de estudos apontados por Tupiassu (2003), onde a função compensatória do ICMS Ecológico pode ser 
substituída por uma consequência incrementadora, observado o crescente número de municípios que passam a adotar políticas ambientais visando o aumento de arrecadação da receita.

Existe uma divergência significativa nas extensões territoriais das UC e dos municípios paraenses. Há casos de municípios extensos, como por exemplo, Altamira, com uma área significativa de UC. Existem municípios pequenos, como Santa Cruz do Arari, com 100\% do seu território constituído de UC. Assim, embora extensões de UC sejam pequenas, essas representam a maior parte ou a totalidade da extensão territorial destes (Tabela 5).

Tabela 5 - Restrição Territorial dos três municípios paraenses mais e menos extensos.

\begin{tabular}{lrrr}
\hline \multicolumn{1}{c}{ Municípios } & $\begin{array}{c}\text { Extensão Territorial } \\
\left(\mathrm{km}^{2}\right)\end{array}$ & UC $\left(\mathrm{km}^{2}\right)$ & $\begin{array}{r}\text { Restrição Territorial } \\
\text { - UC }(\%)\end{array}$ \\
\hline Altamira & $159.695,94$ & $59.443,43$ & $37 \%$ \\
Oriximiná & $107.602,99$ & $70.013,43$ & $65 \%$ \\
Almerim & $72.960,27$ & $33.675,98$ & $46 \%$ \\
Salvaterra & $1.043,50$ & 770,41 & $74 \%$ \\
Santa Cruz do Arari & $1.074,85$ & $1.075,19$ & $100 \%$ \\
São Sebastião da Boa Viista & $1.632,22$ & $1.529,16$ & $94 \%$ \\
\hline
\end{tabular}

Fonte: IDESP (2010a).

\section{PERSPECTIVAS DE UTILIZAÇÃO DO ICMS ECOLÓGICO PARA PSA NO PARÁ}

Ao analisar a experiência pioneira de PSA regulamentada no Estado do Paraná, estudada por Veiga Neto (2008), é possível inferir duas vantagens em relação às perspectivas para o Estado do Pará. A primeira diz respeito ao fato de que as UC de uso sustentável onde residem comunidades são mais frequentes. Assim, os recursos advindos do ICMS Ecológico contribuiriam para a melhoria da qualidade de vida das populações residentes nas UC, colaborando para a adoção de um processo de gestão que inclua esses atores sociais.

A segunda diz respeito ao fato de que, conforme Veiga Neto (2008), a conservação e o bom manejo possuem custos, sendo que o indivíduo que maneja os recursos naturais no sentido de proteger a biodiversidade produz um benefício público. Assim, constitui-se o ICMS Ecológico em um instrumento de incentivo econômico direto às comunidades, baseado na conservação da biodiversidade. 
Portanto, tendo em vista a possibilidade de repasse de parte dos recursos do ICMS Ecológico para os proprietários de RPPN no Paraná, abre-se um precedente para a reflexão da possibilidade de utilização desse mecanismo no Pará como instrumento econômico de financiamento de PSA.

É reconhecido que essa possibilidade tem suas limitações e dificuldades. Como limitação, tem-se que a utilização do ICMS Ecológico como instrumento de financiamento de PSA no Pará, por si só, não se constitui em solução para conservação da biodiversidade. Isso porque, uma das formas de avançar nesse sentido se encontra em um estado mais responsável, efetivo e com mais capacidade de resposta, oferecendo os serviços públicos necessários (GAVENTA, 2003). Portanto, existe a necessidade de que o poder público proporcione políticas públicas que culminem em conservação.

Uma dificuldade que se impõe para o repasse direto dos recursos do ICMS Ecológico é a adaptação das comunidades locais no Pará ao modelo de organização exigido a partir do PSA. Isso porque, no Paraná, o referido repasse aos proprietários de RPPN é realizado a partir da observância dos seguintes critérios: (a) organização de associações, (b) existência da lei do ICMS Ecológico, (c) existência de lei estadual regulamentando convênio entre o município e a associação de proprietários de RPPN, (d) conferência do valor do ICMS Ecológico gerado pela RPPN, por meio de extrato do órgão ambiental, (e) implementação da Comissão Paritária para fiscalização das verbas decorrentes do ICMS Ecológico, (f) elaboração de um projeto de aplicação e gestão das verbas destinadas às RPPN, (g) aprovação do projeto pela Comissão Paritária e (h) assinatura do Termo de Repasse (CEGANA apud VEIGA NETO, 2008). Assim, deve existir um aparato organizacional das instituições de governo envolvidas, bem como organização dos proprietários no tocante a observação dos critérios estabelecidos.

Portanto, no estado do Pará, para adoção do ICMS Ecológico como instrumento de financiamento de PSA, impõem-se desafios como organização e estruturação das instituições envolvidas no processo, bem como das comunidades.

\section{CONSIDERAÇÕES FINAIS}

A implantação do ICMS Ecológico se apresentar como um importante instrumento econômico de financiamento de PSA no Pará. Entretanto, essa possibilidade tem suas limitações e dificuldades. Como limitação, destaca-se que o ICMS Ecológico por si não se constitui em solução para conservação da biodiversidade. Há necessidade de conciliação desse instrumento com políticas 
públicas que culminem em conservação. Adicionalmente, há necessidade, também, de políticas públicas que dêem suporte ao desenvolvimento dos municípios sob uma nova lógica econômica. Os recursos advindos do ICMS Ecológico não são suficientes para desencadear um processo de desenvolvimento em nível municipal.

Os estudos apontam que esse subsídio contribuiria diretamente para a melhoria da qualidade ambiental, desde que as prefeituras atuassem direcionando parte desses recursos ao meio ambiente. Há a necessidade de criação de um mecanismo que garanta a melhoria das condições ambientais nos territórios municipais, que é apontado como o PSA.

Partindo desse pressuposto, há a possibilidade de que parte do ICMS Ecológico, arrecadado pelos municípios, seja repassada às comunidades locais, desde que estas estejam organizadas. Isso porque, ao mesmo tempo em que utilizam os recursos naturais ali presentes, podem contribuir para a conservação e bom manejo, o que incorre em custos. Ao proteger a biodiversidade, esses atores produzem um benefício público. Assim, a conservação pode ser ainda mais potencializada se os interesses das comunidades locais forem considerados aliados no processo de gestão, por meio do PSA.

Uma alternativa seria o estabelecimento de que um dos critérios para a distribuição do ICMS Ecológico pelo estado do Pará para os municípios fosse a "Cota Sustentável". Para este critério seria observada a existência, no território municipal, de comunidades residentes em UC que utilizem boas práticas de manejo dos recursos naturais e protejam a biodiversidade, produzindo assim, um benefício público. Assim, ficaria sob a responsabilidade do ente municipal o financiamento do PSA por meio do repasse de tal recurso para a referida comunidade. A grande dificuldade seria a definição do significado de 'boas práticas'. Para que isso seja possível, é necessário que o planejamento dos recursos a serem aplicados na conservação inclua a participação dos atores sociais nesse processo, pois não só os valores físicos e biológicos devem ser preservados, mas também a qualidade de vida dessas populações e os valores culturais que ao longo da história foram inseridos nas áreas de proteção ambiental.

\section{REFERÊNCIAS}

BORDALO, C. A. L. Gestão Ambiental no estado do Pará. In: ROHA, G. de M. (Org.). Gestão Ambiental: desafios e experiências municipais no estado do Pará. Belém: NUMA/UFPA, EDUFPA, 2007. p. 117-126.

BRASIL. Constituição da Republica Federativa do Brasil 1988. Disponível em: <www.planalto.gov.br/ccivil_03/constituicao/constituiçao.htm>. Acesso em: 12 out. 2009. 
BRASIL. Lei № 9.985, de 18 de Julho de 2000. Disponível em: < http:/ /www. planalto.gov.br/ccivil_03/LEIS/L9985.htm>. Acesso em: 15 ago 2009.

BRITO, D. C.; DRUMMOND, J. O Planejamento e o zoneamento participativos: Novos instrumentos de gestão para as unidades de conservação do Brasil (o caso da área de proteção ambiental do Rio Curiaú - Amapá). RGSA-Revista de Gestão Social e Ambiental, v. 1, p. 112-131, set.-dez. 2007.

BURSZTYN, M. A.; BURSZTYN, M; ASSUNÇÃO, F. N. A. Aspectos legais e institucionais da gestão ambiental na Amazônia. In: SAYAGO, D.; TOURRAN, J. F.; BURSZTYN, M. (Orgs.). Amazônia: cenas e cenários. Brasília: Universidade de Brasilia, 2004. p. 263-293.

FERREIRA, Y. C. de S. M. L.; VASCONCELLOS, M. ICMS Ecológico e Pagamento por Serviços Ambientais (PSA) na Amazônia. In: ENCONTRO NACIONAL DA ASSOCIAÇÃO NACIONAL DE PÓS-GRADUAÇÃO EM ADMINISTRAÇÃO, 34, Rio de Janeiro. Anais... Rio de Janeiro, 2010.

IDESP-Instituto de Desenvolvimento Econômico, Social e Ambiental do Estado do Pará. Zoneamento Econômico e Ecológico do Estado do Pará. Belém: IDESP, 2010a. p. 1-44.

IDESP-Instituto de Desenvolvimento Econômico, Social e Ambiental do Estado do Pará. Desmatamento e Políticas Públicas no Pará. Disponível em: < http:// dialogosdesenvolvimento.blogspot.com/2010/09/desmatamento-e-politicas-publicas-no.html>. Acesso em 20 out. 2010b.

IDESP-Instituto de Desenvolvimento Econômico, Social e Ambiental do Estado do Pará. Indicadores de Qualidade Ambiental (IQA) dos Municípios Paraenses (Versão Preliminar). Belém: IDESP, 2010c. 229f.

LOUREIRO, W. Contribuição do ICMS Ecológico na Conservação da Biodiversidade no Estado do Paraná. 2002. 206 f. Tese (Doutorado na área de concentração em Economia e Política Florestal) - Universidade Federal do Paraná, Curitiba. Disponível em: <http://www.floresta.ufpr.br/pos-graduacao/ seminarios/wilson/contribuicao_do_icms.pdf>. Acesso em: 16 ago. 2009.

Reflexões ICMS Ecológico: a oportunidade do financiamento da gestão ambiental municipal no Brasil. In: LEME, F. C. P. T.; LEME, T. N. Fontes de recursos Financeiros para Gestão Ambiental Pública: cenários e estratégias de captação para o funcionamento de fundos socioambientais. Brasília: Rede Brasileira de Fundos Socioambientais, 2008. p. 81-88. 
MAUÉS, R. H. Uma outra “invenção” da Amazônia: Religiões, Histórias, Identidades. Belém: Cejup, 1999.

NERY, M. A. ICMS Ecológico: Análise do Desenho Brasileiro de um Subsídio Ambiental. 2006. 98 f. Dissertação (Mestrado em Economia) - Centro de Estudos em Economia, Meio Ambiente e Agricultura, Universidade de Brasília, Brasília, 2006.

VEIGA NETO, F. C da. Análise de Incentivos Econômicos nas Políticas Públicas para o Meio Ambiente: O caso do "ICMS Ecológico" em Minas Gerais. 2000. 161 f. Dissertação (Mestrado em Desenvolvimento, Agricultura e Sociedade) - Instituto de Ciências Humanas e Sociais, Universidade Federal Rural do Rio de Janeiro, Rio de Janeiro, 2000.

A Construção dos Mercados de Serviços Ambientais e suas Implicações para o Desenvolvimento Sustentável no Brasil. 2008. 286 f. Tese (Doutorado em Desenvolvimento, Agricultura e Sociedade) - Instituto de Ciências Humanas e Sociais, Universidade Federal Rural do Rio de Janeiro, Rio de Janeiro, 2008.

OLIVEIRA, L. R. M. de O.; JÚNIOR, V. Z.; SPENGLER, E. Gestão Ambiental Compartilhada: Licenciamento Ambiental de Empreendimentos e Atividades com Características de Impacto Local e os Critérios para os Municípios exercerem a Gestão Ambiental. In: LEME, F. C. P. T.; LEME, T. N. Fontes de recursos Financeiros para Gestão Ambiental Pública: cenários e estratégias de captação para o funcionamento de fundos socioambientais. Brasília: Rede Brasileira de Fundos Socioambientais, 2008. p. 22-31.

PARÁ. Constituição do Estado do Pará, 1989. Disponível em: < http:/ / www. pa.gov.br/downloads/Constituicao_do_Para_-_ate_a_EC_43.pdf>. Acesso em: $12 \mathrm{fev}$. 2010.

PARÁ. Decreto n. ${ }^{\circ}$ 1.697, de 5 de junho de 2009. Diário Oficial do Estado do Pará. Belém, PA, 8 jun. 2009. Disponível em: <http://www.ioepa.com.br/site/ diario_online.asp >. Acesso em: 12 fev. 2010.

$P A R A$. Contribuição ao ICMS Ecológico no Pará. Belém: SEMA, s/d.p 1-18.

SECRETARIA DE ESTADO DE MEIO AMBIENTE. Unidades de Conservação Federais, Estaduais e Municipais do Estado do Pará. Belém: SEMA, 2010. Disponível em: < http://www.sectam.pa.gov.br/interna. php?idconteudocoluna=4625> . Acesso em: 20 jan. 2010. 
SECRETARIA DE ESTADO DA FAZENDA. Manual da Cota-parte dos Municípios: ICMS. Belém: SEFA, 2010. Disponível em: < http://www.sefa.pa.gov. br/site/inf_fazendarias/repasse/cotaparte.htm\#p15>. Acesso em: 20 jan. 2010.

SECRETARIA DE ESTADO DA FAZENDA. Repasse de ICMS dos Municípios: Segundo Semestre de 2009. Belém: SEFA, 2009. Disponível em: < http:// www.sefa.pa.gov.br/>. Acesso em: 20 jan. 2010.

SILVA, J. M. P. da. Perfil dos Municípios Paraenses. In: ROHA, G. de M. (Org.). Gestão Ambiental: Desafios e Experiências Municipais no Estado do Pará. Belém: NUMA/UFPA, EDUFPA, 2007. p. 41-51.

TONI, F; PACHECO, P. Gestão Ambiental Descentralizada: um estudo comparativo de três municípios da Amazônia brasileira. Brasilia: Ministério do Meio Ambiente, 2005. 75p.

TUPIASSU, L. V. da C. Tributação Ambiental: utilização de instrumentos econômicos e fiscais na implementação do direito ao meio ambiente saudável. 2003. 294 f. Dissertação (Mestrado em Ciências Jurídicas) - Centro de Ciências Jurídicas, Universidade Federal do Pará, Belém, 2003.

WUNDER, S. et al. Perfil. Pagamentos por Serviços Ambientais: Perspectivas para Amazônia Legal. Brasília: Ministério do Meio Ambiente, 2008. 131 p. 